\title{
Correspondence
}

\section{Patterns of rheumatoid arthritis and systemic lupus erythematosus in Hong Kong}

Sir, Retrospective and cross sectional surveys have suggested a higher prevalence of systemic lupus erythematosus (SLE) and lower prevalence of rheumatoid arthritis (RA) in the Oriental races than in Caucasians. Surveys for SLE have been performed in Hawaii, ${ }^{\text {' Auckland, New }}$ Zealand, ${ }^{2}$ Malaysia, ${ }^{3}$ and Beijing. China ${ }^{+}$and for RA in Japan, ${ }^{5}$ Taiwan. ${ }^{6}$ and China. ${ }^{4}$ None of these studies were population surveys and, being hospital based. were likely to be incomplete since traditional medicine is still practised in these countries. Nevertheless, we would like to report the results of a two year prospective pilot survey of the two diseases in hospitals serving the Chinese living on Hong Kong island. Over $99 \%$ of the population of Hong Kong are Chinese, and this population is relatively stable as there has not been any mass emigration during this period. Patients in Hong Kong may refer themselves to fee paying government clinics of low cost, private general practitioners, practitioners of traditional Chinese medicine, or a combination of the above. Most cases of chronic arthritis eventually present in the government sector because of the high cost of private medicine and patients with SLE particularly tend to be referred by private general practitioners to Queen Mary University Hospital-the only referral centre for Hong Kong island. This hospital is a fee paying government hospital of low cost, and patients with acute systemic illness will usually refer themselves to the emergency department of government hospitals. The government clinics serve as the equivalent of the NHS casualty departments rather than as general practitioners. There is one major and four minor government hospitals on Hong Kong island. The major hospital receives all complicated medical patients and patients that require assessment and monitoring. Our survey was carried out in the major government hospital-Queen Mary, and in one minor hospital-Nethersole.

From July 1983 to June 1985 the number of inpatient admissions with the diagnosis SLE (according to the American Rheumatism Association criteria, 1982), and
RA (according to the New York criteria.1966) and the number of diagnosed new and follow up outpatients wer $\mathbb{\varnothing}$ recorded. The total number of medical inpatient and outpatient referrals were collected at the same time. The prevalence of SLE and RA seen in these two hospitals wa $\vec{D}$ expressed as a percentage of all outpatient and inpatien:medical referrals. The presenting symptoms and signs wer $\vec{\omega}$ noted using a standard assessment sheet. Population figures for Hong Kong island were kindly provided by th Hong Kong government medical and health department

The percentages of patients with SLE and RA of alP medical referrals in these two government hospitals ifo Hong Kong island are shown in Table 1. All the patient seen were Chinese. The annual incidence of SLE for ths population in Hong Kong island derived from the 57 new cases is $2 \cdot 4 / 100000$. This may be an underestimate since we have not reviewed all the minor government or privat hospitals, but the pool of patients in those hospitals likely to be a small fraction of the total figure for the reasons already stated above. Despite this, our estimate of the incidence is greater than most figures quoted foeo Caucasians. ${ }^{7}$ It is interesting that the number of patients with RA seen at these two hospitals is approximately th same as the number with SLE, in contrast with hospitals i the UK. The prevalence of RA in our hospital population is. however. more difficult to assess since the Chinese aro more likely to use traditional remedies for arthritis.

The age of presentation of SLE is younger, analogous tQ a study comparing white Americans with America $\overrightarrow{\bar{B}}$ blacks." There is a marked preponderance of women i] both disease groups. Fig. 1 shows the age of onset in the patients seen at both hospitals. The number of new SLE referrals is greatest in the $0-24$ age group. The nature and prevalence of presenting symptoms, however, were the same as those seen in Caucasians. Antinuclear antibodico were detected in all patients with SLE. In contrast. the a of onset of RA in this Chinese population appears to to similar to that in Caucasians.

These results of a limited prospective survey suggest truf ethnic differences in susceptibility to both RA and SLE. population survey is needed to confirm these findings ant those of previous reports, which suggest a relatively highe incidence and prevalence of SLE. and lower prevalence $₫ \delta$ $\mathrm{RA}$ in Chinese. Studies of genetic markers, for examp?

Table 1 Percentages of patients with SLE and RA of all medical referrals in two government hospitals in Hong Kong

\begin{tabular}{|c|c|c|c|c|c|c|c|}
\hline Hospital & $\begin{array}{l}\text { Total No } \\
\text { of medical } \\
\text { referrals }\end{array}$ & $\begin{array}{l}\text { New } \\
\text { SLE } \\
\text { cases }\end{array}$ & $\begin{array}{l}\text { Total } \\
\text { SLE } \\
\text { cases }\end{array}$ & $\begin{array}{l}S L E \\
\text { prevalence } \\
(\%)\end{array}$ & $\begin{array}{l}\text { Nen } \\
R A \\
\text { cases }\end{array}$ & $\begin{array}{l}\text { Total } \\
R A \\
\text { cases }\end{array}$ & $\begin{array}{l}R A \\
\text { prevalence } \\
(\%)\end{array}$ \\
\hline Queen Mary & 44897 & 46 & 111 & 0.25 & 47 & 142 & 0.32 \\
\hline Nethersole & 7426 & 11 & 22 & $0 \cdot 30$ & 10 & 29 & $0 \cdot 39$ \\
\hline Combined & 52323 & 57 & 133 & 0.25 & 57 & 171 & 0.33 \\
\hline
\end{tabular}




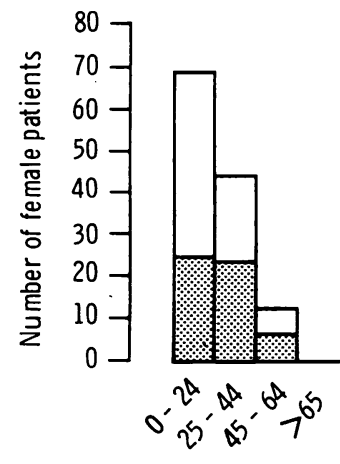

SLE

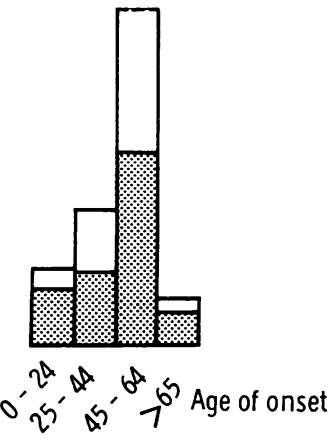

RA

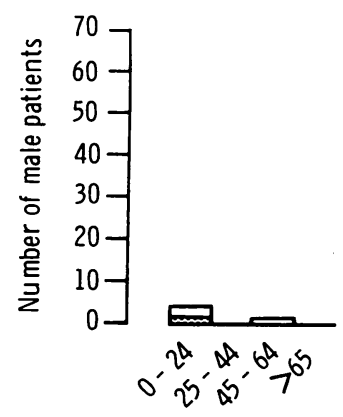

SLE

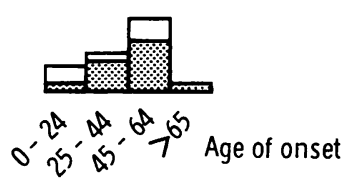

$\mathrm{RA}$
Fig. 1 Histograms to show the age of onset of SLE and RA in male and female patients. The shaded areas represent new referrals during the two year period under study.

HLA, may be useful in explaining these ethnic differences. In this regard the observation that insulin dependent diabetes is associated with DR3/4 in Caucasians but with DR3/9 in Orientals is of interest.

Department of Medicine, Chinese University of Hong Kong

University Medical Unit,

JEAN WOO

Queen Mary Hospital,

Hong Kong

Department of Medicine,

Nethersole Hospital,

Hong Kong

MRC Clinical Research Centre

\& Northwick Park Hospital

Harrow, Middlesex

\section{References}

1 Serdula M K. Rhoads G G. Frequency of systemic lupus erythematosus in different ethnic groups in Hawaii. Arthritis Rheum 1979: 22: 328-33

2 Hart H H. Grigor R R. Caughey D E. Ethnic difference in the prevalence of systemic lupus erythematosus. Ann Rheum Dis 1983: 42: 529-32.
3 Frank A O. Apparent predisposition to systemic lupus erythematosus in Chinese patients in West Malaysia. Ann Rheum Dis 1980: 39: 266-9.

4 Chang N C. Rheumatic diseases in China. J Rheumatol Suppl 1983: 10: 41-5.

5 Shichikawa K. Mayeda A. Komatsubara Y, et al. Rheumatic complaints in urban and rural populations in Osaka. Ann Rheum Dis 1966; 25: 25-31.

6 Palmer-Beasley R, Bennet P H. Chien C L. Low prevalence of rheumatoid arthritis in Chinese. $J$ Rheumatol Suppl 1983; 10: 11-15.

7 Michet C J Jr, McKenna C H, Elveback L R, Kaslow R A. Kurland L T. Epidemiology of SLE and other connective tissue diseases in Rochester. Minnesota, 1950-1979. Mayo Clin Proc 1985; 60: 105-13.

8 Ballou S P, Khan M H, Kushner I. Clinical features of SLE. Differences related to race and age of onset. Arthritis Rheum 1982; 25: 55-60.

\section{Lymphadenopathy in rheumatic patients}

SIR, The paper in the Annals by Drs Kelly, Malcolm, and Griffiths makes the interesting point that lymphadenopathy may be an early feature of inflammatory polyarthritis, and in their series two cases were misdiagnosed and treated by radiotherapy as cases of malignant lymphomata. ${ }^{1}$ In the 1960 s at Westminster Hospital we saw two similar cases, a 15 year follow up showing only rheumatoid disease and no malignancy. The fact that lymph node enlargement was common in relation to inflamed arthritic joints did not seem to be appreciated by my fellow examiners in the Membership examinations of the late 1960 s, hence the article quoted by Kelly et al (Robertson et al $1968^{2}$ ).

A review of the case records of 35 patients treated between 1950 and 1966 at Westminster Hospital for giant follicular lymphoma by radiotherapy showed at that time no evidence of inflammatory arthritis of any sort. Of the 100 cases of rheumatoid arthritis we reported in $1968,{ }^{2}$ $82 \%$ had lymph node enlargement compared with $52 \%$ in the control series matched for age and sex, figures much higher than those of Short et al who found $29.4 \%$ in those with rheumatoid arthritis and $8.9 \%$ in controls. ${ }^{3}$ As in our study all palpable glands were reported and an attempt was made to grade their enlargement. In our study we found glands most commonly and most enlarged in axillae, inguinal, and epitrochlear areas in relation to actively inflamed joints, but cervical nodes were present in arthritic and control subjects in equal number $(26 \%$ and $23 \%)$ and were of similar size. Lymphograms done in 15 patients with rheumatoid arthritis by W F White showed non-specific inflammatory changes which, though different from malignant lymphoma, were not sufficiently distinctive to be diagnostic. We therefore considered lymph node enlargement a common finding in adult patients, in relation to inflamed joints, but only rarely part of a generalised lymphadenopathy (as in Felty's syndrome), though this is seen in young patients with chronic juvenile arthritis more often. Kelly et al point out that in inflammatory arthritis, lymphadenopathy may occur early on in 